\title{
A INFLUÊNCIA DA DANÇA NO DESENVOLVIMENTO DA COORDENAÇÃO MOTORA EM CRIANÇAS COM SÍNDROME DE DOWN
}

Aline Vidal Maia

Sérgio Ricardo Boff

\section{Resumo}

A dificuldade que um indivíduo com Síndrome de Down (S. D.) tem de se tornar independente, está relacionado a um bom tratamento, visando à melhora em longo prazo, isto poderia ser amenizado através da dança. $\mathrm{O}$ objetivo desse trabalho é verificar o auxilio oferecido pela dança nos índices de coordenação motora de crianças com S. D. A pesquisa foi realizada com 20 crianças portadoras de S. D. de ambos os sexos, com idade entre 2 a 6 anos, formando 2 grupos com 10 crianças cada um, sendo um grupo com crianças que praticam a dança e outro com crianças que não praticam. Em que o nível de coordenação motora foi avaliado pelo teste de dança: Atividades de Movimentos Criativos do Projeto Spectrum de Barrow \& McGreen. Após a realização dos testes comparamos os grupos, de crianças que dançam com o outro grupo.

\section{Palavras-Chave}

Síndrome de Down; Dança; Desenvolvimento motor.

\section{THE INFLUENCE OF THE DANCE IN THE DEVELOPMENT OF THE MOTOR COORDINATION IN CHILDREN WITH DOWN SYNDROME}

Aline Vidal Maia

Sérgio Ricardo Boff

\begin{abstract}
The difficulty that a person with Down Syndrome (D.S) has to become independent. This is related to a good treatment aiming the improvement of the patient in long time, this could be done through the dance. The objective of this work is check the support offered by the dance at the rate of the motor coordination in children with D.S. The research was conducted with 20 children with D.S from both sex, with ages between 2 and 6 years composing 2 groups with 10 children each one, one group with children who practice the dance and another with children who don't practice. The level of motor coordination was evaluated by the dance's test: Creative Movements Activities from the Spectrum of Barrow \& McGreen Project. After the tests, we compared the groups of children who dance and the other one.
\end{abstract}

\section{Key-Words}

Down Syndrome; Dance; Motor coordination. 


\section{INTRODUÇÃO}

A Síndrome de Down (SD), descrita por John Langdon Down, é uma condição genética onde apresenta alterações cromossômicas que geram mudanças fenotípicas presentes já no nascimento do bebê, com alterações no comportamento e desenvolvimento da inteligência não dependendo exclusivamente dessa alteração cromossômica, desta forma as limitações do desenvolvimento podem ser superadas, desde que essa criança seja estimulada intensamente e que essa estimulação perdure até a fase adulta (SCHWARTZMAN, 1999).

Cooley (1991) citou outros problemas de saúde que podem ocorrer no portador da SD: cardiopatia congênita (40\%); hipotonia (100\%); problemas de audição (50 a 70\%); de visão (15 a 50\%); alterações na coluna cervical (1 a 10\%); distúrbios da tireóide (15\%); problemas neurológicos (5 a 10\%); obesidade e envelhecimento precoce, alem disso, os portadores da SD possuem dificuldades de ajustes ou mudanças, relacionados fundamentalmente com parâmetros do movimento. Eles possuem uma dificuldade do controle postural, ocasionado por alterações no sistema vestibular o que resulta em uma forma de andar diferenciada (GIMENEZ, 2005).

Quando falamos de SD, sempre se enfocam os limites do indivíduo e não aquilo que ele é capaz de fazer. Vários trabalhos realizados sugerem que a privação de uma fonte de informação sensorial pode implicar a utilização de outro meio para coleta de informações, ou seja, a restrição de certos movimentos faz com que esses indivíduos utilizem outra via para o envio de comandos musculares. Portanto, tanto os adultos quanto as crianças podem apresentar capacidades para lidar adequadamente com as suas restrições motoras, refletindo assim padrões de movimentos diferenciados indicando que esses indivíduos dispõem de recursos para lidar com as suas tarefas motoras (GIMENEZ, 2005).

Segundo Tolocka (2000), o termo atraso de desenvolvimento, dado as diferenças que podem ser notadas no desenvolvimento motor de uma criança com SD se comparadas com crianças sem essa síndrome é inadequado, pois o que se apresenta na verdade são desvios de desenvolvimento e não atrasos. Com relação aos estudos feitos sobre a agilidade de pessoas com SD em responder a estímulos, concluiu-se que isto poderia significar que esses indivíduos desejariam realizar o movimento mais lentamente para conseguir atingir mais precisão, sendo uma diferença devido à estratégia adotada para controle motor e não necessariamente uma diferença biológica, portanto considerada uma reação adaptativa. 
Com relação ao desenvolvimento motor de uma criança com SD podemos dizer que existe uma grande extensão no período de realizações, em que uma variedade de fatores pode ocasionar um atraso nesse desenvolvimento, se comparada com crianças não portadoras de $\mathrm{SD}$, como defeitos cardíacos congênitos, fraqueza muscular ou outros problemas biológicos. O movimento de sentar, por exemplo, tem o seu considerável atraso devido parcialmente à fraqueza dos músculos do pescoço, o mesmo ocorre com o processo de engatinhar, pois a criança muitas vezes não tem força muscular suficiente nos braços, ombros e tronco. $\mathrm{O}$ ato de ficar em pé e andar estão muitos relacionados e apresentam características que podem estar presentes ainda na marcha de uma criança com SD como: as pernas ficam muito abertas, os joelhos direcionados para fora e voltados levemente para trás e os pés achatados contra o chão. Devido o processamento mais lento de informações, pode demorar mais para se obter sinais de curiosidade e iniciativa na criança com SD, entretanto, com ajuda adequada, a aprendizagem ocorre, de fato, embora em ritmo mais lento (CLAIRE, 1998).

Estudos realizados por Mancini (2003) sobre o desempenho funcional de crianças com SD comparados com crianças com o desenvolvimento normal aos 2 e 5 anos nos mostram que apesar dos grupos apresentarem desempenho em mobilidade significativamente diferente aos 2 anos, os resultados demonstraram que essa diferença não é significativa aos cinco anos de idade. $\mathrm{O}$ crescimento e o desenvolvimento de crianças com SD se aproxima daquele apresentado por crianças normais, no que se refere a habilidades motoras globais. Sugerindo que à medida que a criança com SD vai adquirindo habilidades na área de mobilidade, estas habilidades parecem ser incorporadas no repertório diário da mesma, ganhando também independência nesta área de função.

Uma maneira de se adquirir habilidades na área da mobilidade é na fase pré-escolar que é fundamental para a formação e maturação desses indivíduos, pois ela passa a participar de um mundo mais amplo, sendo interessante para os pais que observem o desempenho dessa criança fora de casa, já que uma relação muito próxima não ajuda nem aos pais e nem a desenvolver uma independência dessa criança com relação ao mundo. Colocar uma criança com SD em qualquer tipo de escola, desde que esta possua um programa de boa qualidade, pode oferecer para estes indivíduos a alegria da descoberta, para que no futuro estas mesmas crianças possam apresentar um melhor desempenho, pois foram incentivadas a tentar e a crescer, ou seja, progredir para o seu potencial máximo (CANNING, 1998). 
O desenvolvimento motor implica em um ganho de competências, entendida como a capacidade de se ajustar, adaptar e modificar o ambiente em que vive. Esse processo deverá ser contínuo e acentuado nos primeiros anos de vida, porém não se pode deixar de lado que ele ocorre ao longo de toda a vida do ser humano, ou seja, é um processo permanente de aprender a mover-se com controle e competência, em relação aos desafios que enfrentam diariamente (GONZALES, 2006).

Quando nos referimos em ensinar a dança para pessoas cujo corpo apresenta uma deficiência é importante ressaltar que a palavra ensino tem que ser colocada como a ação do professor em despertar e orientar o aluno para o movimento, deixando-o livre para desenvolver qual o gesto adequado para expressar como o aluno percebeu e percebe aquilo que lhe é proposto. Não aquele ensino, que vem do comando do que deve ser feito, que imprime um modelo, que se antecipa autoritariamente, definindo qual gesto é harmonioso, para a justeza do movimento (BARNABE, 2001).

E interessante enfatizar que na dança o que se busca trabalhar não é o corpo-objeto, onde somente interessa a execução do movimento, o que se busca é a participação de todos, vivendo, expressando e pensando seu próprio movimento, atuando com sua subjetividade, para que possam criar e agir com autonomia. A linguagem da expressão corporal e da dança é percebida, em vários níveis simultâneos, por exemplo: ela pode ser uma potência altamente significativa de linguagem simbólica que utiliza (em termos de movimento, espaço e tempo) todas as faculdades do ser humano, tanto cognitivas, como físicas e afetivas, caracterizada pelo uso rítmico harmonioso, e isso se dá pelo fato de ao dançar os músculos, os sentidos e a mente entram em atividade, combinando-se reciprocamente, comunicando pensamentos e emoções (OLIVEIRA, 2006).

Uma maneira bem eficiente de se trabalhar a dança com os portadores de SD e utilizar a dança educacional recreativa, sendo uma excelente forma de estabelecer a saúde, aptidão física, auto confiança, equilíbrio emocional, integração social, entre outros benefícios por ser um método que não se preocupa com a técnica, e sim, propõe que as pessoas adaptem os exercícios ao seu dia-a-dia, seu meio, proporcionando liberdade de movimentos.

Segundo Zausmer (1998), o auxilio precoce a uma criança com SD, é essencial para desenvolver os interesses e habilidades necessários para a realização de uma variedade de atividades físicas e recreacionais, como dançar acompanhando ritmos com o movimento. A dança pode auxiliar em movimentos básicos para a criança como pular e saltitar, ou se colocados em formas mais competitivas, a 
dança pode enriquecer muito a vida desses indivíduos, assim tornando suas habilidades corporais o meio mais valioso de competição.

\section{OBJETIVO}

Verificar o efeito da dança sobre a coordenação motora de crianças portadoras de Síndrome de Down, comparando os índices, entre crianças praticantes e não praticantes de dança.

\section{METODOLOGIA}

A pesquisa foi realizada com 20 crianças de ambos os sexos portadoras de SD, divididas em dois grupos; um grupos com 10 crianças ( 3 meninos e 7 meninas) que tenham a dança como forma terapêutica a pelo menos 1 ano, outro grupo formado por 10 crianças ( 3 meninos e 7 meninas) que não utilizem a dança como forma de tratamento, para esta avaliação foi aplicado o Projeto Spectrum, SPFI, procedimentos de escores para movimentos criativos, 1989 (BARROW, 2003).

O procedimento envolve a avaliação em seis componentes: sensibilidade rítmica, controle corporal, dinâmica de movimentos, uso do espaço, idéias geradas de movimentos e responsividade à música. $\mathrm{O}$ avaliador confere pontos a cada criança, em cada componente avaliado, um resultado 1 (baixo desempenho na habilidade), 2 (médio desempenho na habilidade) ou 3 (alto desempenho na habilidade) é assinalado em cada componente.

Os testes foram realizados nos horários em que essas crianças estariam nas suas respectivas instituições de ensino terapêutico, de maneira a não atrapalhar as suas atividades diárias e sem tirá-las da rotina em que já estão habituadas, os resultados alcançados individualmente foram colocados na forma de tabela separada por grupos de crianças, a fim de comparar os resultados obtidos. As que não utilizam a dança como forma de atividade terapêutica e crianças que utilizam a dança como atividade terapêutica. A comparação dos resultados foi feita através da pontuação conseguida por cada indivíduo em cada um dos componentes avaliados.

\section{RESULTADOS}

$\mathrm{Na}$ Tabela 1 encontram-se os resultados da comparação das freqüências (\%) nos testes de sensibilidade rítmica (A), controle corporal (B), dinâmica de movimento (C), uso do espaço (D), idéias geradas de movimentos $(\mathrm{E})$, responsividade a música $(\mathrm{F})$, entre as crianças praticantes de dança e não praticantes de dança. 
Observou-se que no teste A $20 \%$ das crianças que praticam dança receberam 1 ponto, $40 \%$ receberam 2 pontos e 40\% receberam 3 pontos; em relação às crianças que não praticam dança, observou-se que $90 \%$ receberam 1 ponto e $10 \%$ receberam 2 pontos. Ou seja, nesta atividade as crianças que praticam dança apresentaram desempenho melhor quando comparadas com as crianças não praticantes de dança.

No teste B $10 \%$ das crianças que praticam dança receberam 1 ponto, $60 \%$ receberam 2 e $30 \%$ recebeu 3 pontos; enquanto que as crianças que não praticam o resultado foi de $70 \%$ com 1 ponto e $30 \%$ com 2 pontos. Sendo assim, o grupo que pratica dança obteve um resultado melhor em comparação com o grupo que não dança.

Quando observamos o teste C verificamos que o grupo praticante de dança obteve $30 \%$ das crianças com 1 ponto, $60 \%$ com 2 pontos e $40 \%$ com 3 pontos; já o grupo não praticante de dança obteve $60 \%$ das crianças com 1 ponto e $40 \%$ com 2 pontos. Portanto o grupo praticante de dança obteve resultados melhores do que o grupo de crianças que não praticam a dança.

Verificou-se no teste D 10\% das crianças que praticam dança com 1 ponto, $30 \%$ com 2 pontos e $60 \%$ com 3 pontos; já as crianças que não praticam a dança a freqüência foi $70 \%$ com 1 ponto e $30 \%$ com 2 pontos. Ou seja, os praticantes de dança obtiveram freqüências melhores em comparação com os não praticantes.

No teste E podemos observar que $40 \%$ das crianças praticantes de dança conseguiram 1 ponto, 30\% 2 pontos e $30 \% 3$ pontos; enquanto $80 \%$ das crianças que não praticam dança alcançaram 1 ponto e $20 \% 2$ pontos. Assim o grupo praticante de dança também foi melhor em comparação com o grupo que não dança.

Quando observamos o teste $\mathrm{F}$ verificamos que 40\% das crianças que dançam alcançaram 1 ponto, 30\% 2 pontos e 30\% 3 pontos; ao observar o grupo de crianças que não dançam observamos $80 \%$ delas alcançaram 1 ponto e $20 \% 2$ pontos. Sendo assim o grupo das crianças que dançam obtiveram um resultado melhor do que as crianças que não dançam. 
Tabela 1- Comparação das freqüências (\%) nos testes de sensibilidade rítmica (A), controle corporal (B), dinâmica de movimento (C), uso do espaço (D), idéias geradas de movimentos (E), responsividade a música (F), entre as crianças praticantes de dança e não praticantes de dança.

\begin{tabular}{|c|c|c|c|c|c|}
\hline \multirow{2}{*}{ Atividades Pontuaçăo } & \multicolumn{3}{|c|}{ PRATICANTES DE DANCA } & \multicolumn{2}{|c|}{ NAOO PRATICANTES DE DANCA } \\
\hline & 1 & 2 & 3 & 1 & 2 \\
\hline$\overline{\mathrm{A}}$ & 20 & 40 & 40 & 90 & 10 \\
\hline B & 10 & 60 & 30 & 70 & 30 \\
\hline C & 30 & 30 & 40 & 60 & 40 \\
\hline D & 10 & 30 & 60 & 70 & 30 \\
\hline $\mathrm{E}$ & 40 & 30 & 30 & 80 & 20 \\
\hline $\mathrm{F}$ & 20 & 30 & 50 & 70 & 30 \\
\hline
\end{tabular}

Em pesquisa citada por Moreira (2000), em que ao analisar o efeito da estimulação psicomotora em grupos com Síndrome de Down pode-se observar que as crianças que foram estimuladas obtiveram um desenvolvimento melhor, ao contrário das crianças que não sofreram esse estímulo, fato como este vem a confirmar os resultados alcançados na presente pesquisa, porém não com estímulos específicos na área psicomotora, mas na área da coordenação motora, áreas estas que se relacionam indiretamente.

Uma das habilidades testada foi o equilíbrio, através da atividade de controle corporal e dinâmica de movimento. A tabela das crianças que dançam apresenta um índice significativamente melhor, comparado ao outro grupo de crianças analisado.

Segundo Gorla (2001), o equilíbrio é fundamental para a coordenação motora, e um mau equilíbrio afeta a construção do esquema corporal, sendo imprescindível a continuidade sistemática e crescente das atividades para consolidar gradualmente este equilíbrio. Em seu estudo foram realizados testes de coordenação motora com crianças portadoras de SD, porém com faixa etária e metodologia diferenciada da pesquisa aqui realizada. No entanto verificam-se melhoras em algumas das crianças que foram estimuladas e foi concluído, em seu estudo dentre outras coisas, que o estímulo tanto quantitativo como qualitativo, estimulação do desenvolvimento perceptivo-motor são necessários nesse grupo de crianças.

Outro estudo realizado por Strijker (2006), sobre o desenvolvimento infantil em crianças normais conclui, dentre outras coisas, que os movimentos aprendidos durante os primeiros 6 anos de vida, caracterizam a base para as aprendizagens numa etapa posterior. Desta forma, se uma criança for pouco estimulada ou apresentar déficits do desenvolvimento motor na primeira infância, estes se refletirão em 
sua vida adulta, período em que os movimentos realizados representam uma linha de continuidade de todo o conteúdo motor aprendido e armazenado na infância, por meio de nossa memória motora. Assim, temos que reconhecer que a infância é a etapa mais importante a caminho da maturidade neurológica e psicológica, razão pela qual temos a necessidade de garantirmos que as atividades motoras da infância representem concretamente, a oportunidade de vivências corporais e de desenvolvimento global para estas crianças.

Apesar do estudo citado a cima se referir a criança normal e o estudo discutido ser com crianças com SD, não se pode descartar a idéia proposta por Canning (1998), de que com esse grupo a estimulação precoce é fundamental e as habilidades adquiridas serão essenciais para o desenvolvimento dessa criança. De acordo com os resultados apresentados das crianças que dançam, elas adquiriram habilidades que serão úteis para a vida adulta, como por exemplo, a melhora no desempenho na atividade de idéias geradas de movimentos, em comparação com o outro grupo analisado.

O que se torna exemplificado com essa pesquisa é justamente o que diz Zausmer (1998), em que as limitações físicas e intelectuais da criança com SD podem ser modificadas por meio do manejo competente e do treinamento precoce, mediante uma intervenção que focalize a melhoria do desenvolvimento sensório-motor e social.

\section{CONCLUSÃO}

A partir desses resultados podemos concluir que as hipóteses inicialmente feitas foram atingidas, pois a prática da dança em crianças portadoras de SD realmente oferece índices melhores de desenvolvimento motor.

A comparação dos dados, se encontra no gráfico de desempenho das crianças nas atividades de movimentos criativos, em que fica mais claro a observação da influência benéfica que a dança pode proporcionar desde que, realizada de maneira a respeitar os limites que as crianças com SD podem vir a apresentar. 


\section{REFERÊNCIAS}

BARNABÉ, R. Dança e deficiência: proposta de ensino. 2001. 115f. Dissertação (Mestrado) Faculdade de Educação Física, Universidade Estadual de Campinas, Campinas, 2001.

BARROW, H. M.; McGREEN, R. Medida e avaliação em educação física e esportes. 5. ed. Barueri: Manole, 2003.

CANNING, C. D. Os anos pré-escolares. In: PUESCHEL, S. Sindrome de Down guia para pais e educadores. 3. ed. Campinas: Papirus, 1998.

COOLEY, W. C; GRAHAM, J. .M. Down syndrome: an update and review for the primary pediatriacian. Clin Pediat. v. 30, p. 233-53, 1991.

CLAIRE, D. C.; PUESCHEL, S. M. Expectativas de desenvolvimento: visão panorâmica. In: PUESCHEL, S. Síndrome de Down: guia para pais e educadores 3 ed. Campinas: Papirus, 1998.

GIMENEZ, R.; MANOE, E. J. Comportamento motor e deficiência: considerações para pesquisa e intervenção. In: TANI, G. Comportamento motor aprendizagem e desenvolvimento. Rio de Janeiro: Guanabara Koogan, 2005.

GONZALES, J. S. Benefícios da dança nos aspectos cognitivos motores e sócio - afetivos. 2006. $31 \mathrm{f}$. Monografia (Licenciatura Plena em Educação Física) - Faculdade de Educação Física da ACM de Sorocaba, Sorocaba, 2006.

GORLA, J. I. Coordenação motora de portadores de deficiência mental: avaliação e intervenção. 2001. 154f. Dissertação (Mestrado) - Faculdade de Educação Física, Universidade Estadual de Campinas, Campinas, 2001.

MANCINI, M. C. et al. Comparação do desempenho funcional de crianças portadoras de Sindrome de Dowm e crianças com desenvolvimento normal os 2 e 5 anos de idade. Arq. Neuropsiquiatr, v. 61, n.

2B, p. 409-415, 2003.

MOREIRA, L. M. A.; HANI, C. N. E; GUSMÃO, F. A. F. A síndrome de Down e sua patogênese: considerações sobre o determinismo genético. Revista Brasileira de Psiquiatria, v. 22, n. 2, p. 96-99, 2000 .

NANNI, D. Dança educação. Rio de Janeiro: Sprint, 1995.

OLIVEIRA, L.; et al. Dança e o desenvolvimento motor de portadores de necessidades educativas especiais: PNEEs. Disponível em: < www.ufsm.br/ce/revista/ceesp/2002/02/a6.htm> Acesso em: 08 maio. 2006. 
PUESCHEL, S. M. Causas da síndrome de down. In: PUESCHEL, S. Síndrome de Down guia para pais e educadores. 3. ed. Campinas: Papirus, 1998.

SCHWARTZAMAN, J. S. et al. Síndrome de Down. São Paulo: Mackenzie, 1999.

TOLOCKA, R. E. Estabilidade motora de pessoas portadoras de sindrome de Down, em tarefas de desenhar. 2000. 190f. Tese (Doutorado) - Faculdade de Educação Física, Universidade Estadual de Campinas, Campinas, 2000.

WEAVER, S.; CANNING, C. D. Recreação. In: PUESCHEL, S. Síndrome de Down guia para pais e educadores. 3. ed. Campinas: Papirus, 1998. Cap. 19.

ZAUSMER, E. Estimulação do desenvolvimento da motricidade grossa. In: PUESCHEL, S. Síndrome de Down guia para pais e educadores. 3. ed. Campinas: Papirus, 1998. . 


\section{Aline Vidal Maia \\ Faculdade de Educação Física - FEFISO ACM- Sorocaba}

\section{Sérgio Ricardo Boff}

Faculdade de Educação Física- FEFISO ACM - SOROCABA

\section{Referência do artigo:}

\section{ABNT}

MAIA, A. V., BOFF, S. R. A influência da dança no desenvolvimento da coordenação motora em crianças com Síndrome de Down. Conexões, v. 6, p. 144-154, 2008.

\section{APA}

Maia, A. V., \& Boff, S. R. (2008) A influência da dança no desenvolvimento da coordenação motora em crianças com Síndrome de Down. Conexões, 6, 144-154.

\section{VANCOUVER}

Maia AV, Boff SR. A influência da dança no desenvolvimento da coordenação motora em crianças com Síndrome de Down. Conexões, 2008; 6: 144-154. 